\title{
Oceansat-2 and RAMA buoy winds: A comparison
}

\author{
S Indira Rani* and M Das Gupta \\ National Centre for Medium Range Weather Forecasting (NCMRWF), \\ A-50, Institutional Area, Sector-62, Noida 201 309, India. \\ *Corresponding author.e-mail: indira@ncmrwf.gov.in_ranispl@gmail.com
}

Sea surface vector winds from scatterometers onboard satellites play an important role to make accurate Numerical Weather Prediction (NWP) model analysis over the data sparse oceanic region. Sea surface winds from Oceansat-2 scatterometer (OSCAT) over the Indian Ocean were validated against the Research Moored Array for African-Asian-Australian Monsoon Analysis and Prediction (RAMA) buoy winds to establish the accuracy of OSCAT winds. The comparison of OSCAT winds against RAMA buoy winds for a period of one year (2011) shows that the wind speeds and directions derived from OSCAT agree with RAMA buoy winds. The monthly mean wind speeds from both OSCAT and RAMA buoy show maximum value during the monsoon period as expected. In the complete annual cycle (2011), the monthly mean root mean square differences in the wind speed and wind direction were less than $\sim 2.5 \mathrm{~ms}^{-1}$ and $\sim 20^{\circ}$, respectively. The better match between the OSCAT and RAMA buoy wind is observed during Indian summer monsoon (June-September). During monsoon 2011, the root mean square differences in wind speed and wind direction were less than $1.9 \mathrm{~ms}^{-1}$ and $11^{\circ}$, respectively. Collocation of scatterometer winds against equatorial and off-equatorial buoys clearly brought out the monsoon circulation features. Collocation of Advanced Scatterometer (ASCAT) winds on-board European Space Agency (ESA) MeTop satellite with respect to RAMA buoy winds during monsoon 2011 also showed that the OSCAT wind statistics are comparable with that of ASCAT over the Indian Ocean, and indicates that the accuracy of both the scatterometers over the Indian Ocean are essentially the same.

\section{Introduction}

Among the three tropical oceans, Pacific, Atlantic and Indian Ocean, the Indian Ocean is unique in that it is blocked at $25^{\circ} \mathrm{N}$ by the Asian landmass. The Indian Ocean receives heat from the other two tropical oceans, Pacific via the Indonesian Throughflow (Gordon 2001) and exports heat to the Atlantic via the Aguhlas Current System (de Ruijter et al. 1999). The monsoon circulation, because of the seasonal heating and cooling of the land, sets the wind reversal and intense rainfall over the Indian subcontinent. Since the northern limit of the Indian Ocean is blocked by the Asian landmass, the currents cannot carry heat from the tropics to the higher northern latitude as in the other oceans. The anomalies in the Indian Ocean climate affect the evolution of El NinoSouthern Oscillation (ENSO), the North Atlantic Oscillation (NAO), rainfall, hurricane activity, the atmospheric circulation of the North Pacific, and western U.S. weather through atmospheric teleconnections (McPhaden et al. 2009 and the references therein). However, the lack of potential data over the Indian Ocean limits our knowledge of key potential features of ocean-atmospheric

Keywords. Oceansat-2 (OSCAT); RAMA buoy; ASCAT. 
coupling and the monsoon circulation. The Research Moored Array for African-Asian-Australian Monsoon Analysis and Prediction (RAMA) buoy network over the Indian Ocean, part of the Tropical Atmosphere Observation (TAO) program helps to fill this data void to a good extend. The RAMA buoy network provides data to validate the scatterometer winds over the Indian Ocean region. The scatterometer wind verification generally rely on the comparison between wind models and the sensor data, or on the inter-comparison with meteorological buoy data (Portabella and Stoffelen 2009; Stoffelen et al. 2010; Vogelzang et al. 2011; Chakraborty et al. 2012).

Oceansat-2 is the second Indian satellite dedicated to ocean research, a continuity of the operational services of Oceansat-1 with high application potentials. The Oceansat-2 was launched from Satish Dhawan Space Centre, Sriharikota on 23rd September, 2009, using Polar Satellite Launch Vehicle (PSLV-C14). It has three payloads: (i) Ocean Colour Monitor (OCM), (ii) Ku-band Pencil Beam Scatterometer (OSCAT) developed by Indian Space Research Organization (ISRO), and (iii) Radio Occultation Sounder for Atmosphere (ROSA) developed by the Italian Space Agency. The mission goal of Oceansat-2 is to provide wind speed measurements of $4-24 \mathrm{~ms}^{-1}$, with an accuracy of $2 \mathrm{~ms}^{-1}$, and direction, with an accuracy of $20^{\circ}$. The scatterometer, a $\mathrm{Ku}$-band pencil beam sensor similar to that onboard QuikSCAT satellite, provides surface vector winds over global oceans with a two-day repeativity. Singh et al. (2011) illustrated the impact of the assimilation of OSCAT surface winds in WRF.

Sea surface wind products from scatterometers flown onboard satellites play an important role to create accurate Numerical Weather Prediction (NWP) model analysis over the data sparse oceanic region. In this paper, authors attempted to validate the OSCAT wind products with respect to RAMA buoy winds over the Indian Ocean in order to bring out whether the errors in OSCAT derived wind speed and direction are within the mission goal over the Indian Ocean, so that OSCAT wind products can be assimilated in NWP models.

Numerous studies have been reported on the comparison of scatterometer wind observations from different space borne platforms over the Indian Ocean with buoy observations. Goswami and Sengupta (2003) carried out a comparison of QuikSCAT with two buoys in the Indian Ocean and the Root Mean Square Vector Difference (RMSVD) was observed to be $1.4 \mathrm{~ms}^{-1}$ for both zonal and meridional components. Goswami and Rajagopal (2003) showed the impact of scatterometer data assimilation in numerical models to improve the weather forecast over India. Satheesan et al. (2007) evaluated the performance of QuikSCAT wind vectors against in-situ buoy observations over the Indian Ocean and reported the mean difference in wind speed and wind direction as $0.37 \mathrm{~ms}^{-1}$ and $5.8^{\circ}$ and the root mean square deviations as $1.57 \mathrm{~ms}^{-1}$ and $44.1^{\circ}$ averaged over a period of 2000-2003. Sudha and Prasada Rao (2013) compared the OSCAT winds against RAMA buoy (considered 8 buoys) winds over the Indian Ocean and Triangle Trans-Ocean Buoy Network (TRITON) (considered 6 buoys) over the Pacific Ocean and reported that the OSCAT wind speed errors are within the mission goal, but the wind direction errors are higher than the mission goal and the OSCAT wind speeds are relatively more accurate over the Indian Ocean.

In this paper, the OSCAT ocean surface winds over the Indian Ocean were validated against the RAMA buoy ( 16 buoys) winds for a period of one year, 2011. For a better assessment of the OSCAT winds over the Indian Ocean in comparison to other scatterometer winds available, the ASCAT winds were also compared with respect to RAMA buoy winds during monsoon 2011. Even though there is difference in the configuration and frequency of OSCAT (Ku-band) and ASCAT (Cband), a comparison of two datasets with respect to an independent dataset (RAMA buoy) will give a better evaluation. Four buoys near the equator, four north of equator and eight south of equator were considered in the present study. The data used in this study is described in section 2, followed by the methodology in section 3 . The results from the present study are discussed in section 4, and the main findings from the study are concluded in section 5 .

\section{Data}

\subsection{Scatterometer data}

ISRO reprocessed OSCAT Level-2B (L2B) wind data (version 1.3, released in December 2011) is available through National Remote Sensing Centre (NRSC) (www.nrsc.gov.in). The OSCAT wind vector product generation is based on the algorithms by Gohil et al. (2008, 2010). In this study, the performance of ISRO reprocessed OSCAT winds were compared with respect to RAMA buoy winds. National Centre for Medium Range Weather Forecasting (NCMRWF) is regularly assimilating ASCAT wind data from National Oceanic and Atmospheric Administration/National Environmental Satellite, Data, and Information Service (NOAA/NESDIS) since June 2011 in its global model, T574L64. In this study, ASCAT winds during monsoon 2011 also compared against 
RAMA buoy winds. This type of exercise gives a better understanding on the quality of OSCAT winds in terms of other existing scatterometer winds. Figure 1 shows the coverage of OSCAT and ASCAT ocean surface winds received at NCMRWF during different six hourly global model assimilation cycles on a particular day. Figure 1(a) is the scatterometer wind coverage data received
NCMRWF during 00 UTC (00 \pm 3 UTC) assimilation cycle on a particular day. Similarly, figure $1(b-d)$ are the scatterometer wind coverage received at NCMRWF during $06 \mathrm{UTC}(06 \pm 3$ UTC), 12 UTC (12 \pm 3 UTC), and 18 UTC (18 \pm 3 UTC) assimilation cycles on a particular day. From figure 1, it is clear that both the scatterometers are complementing each other. The orbital (a)

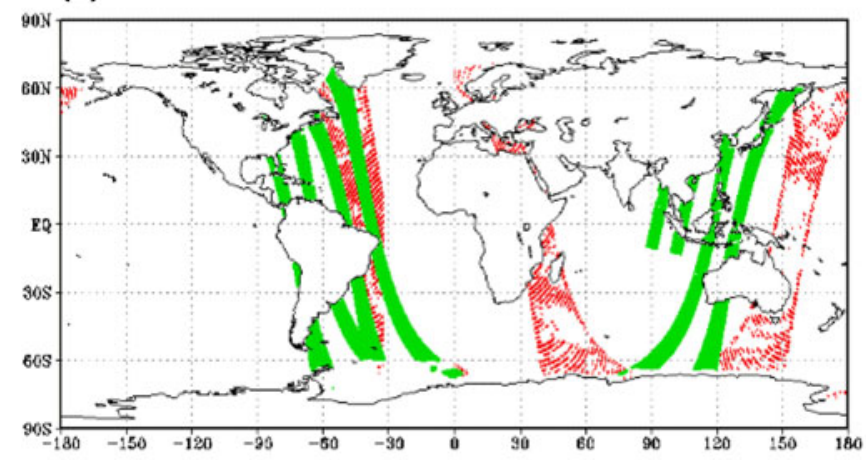

(c)

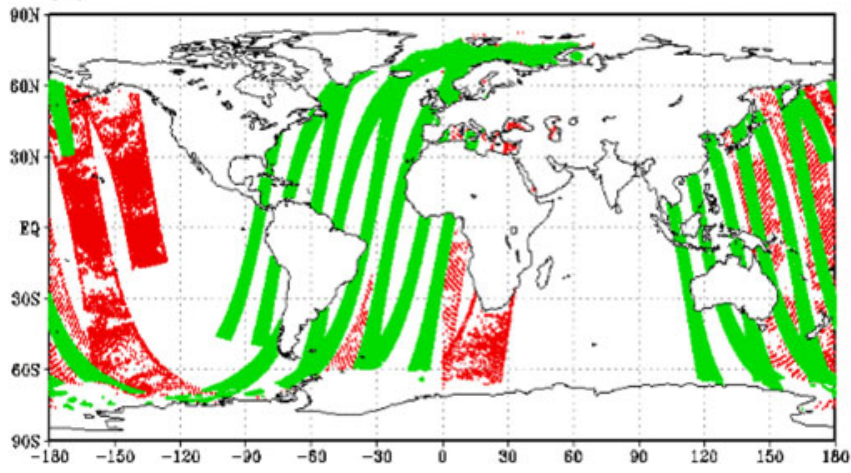

(b)

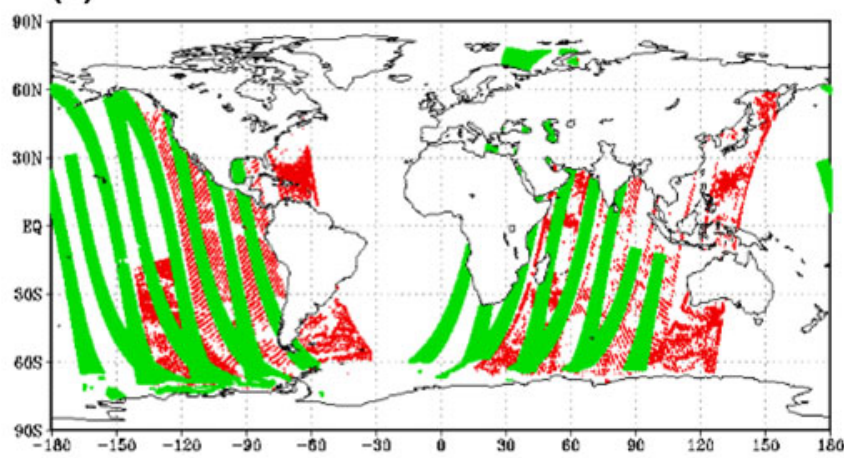

(d)

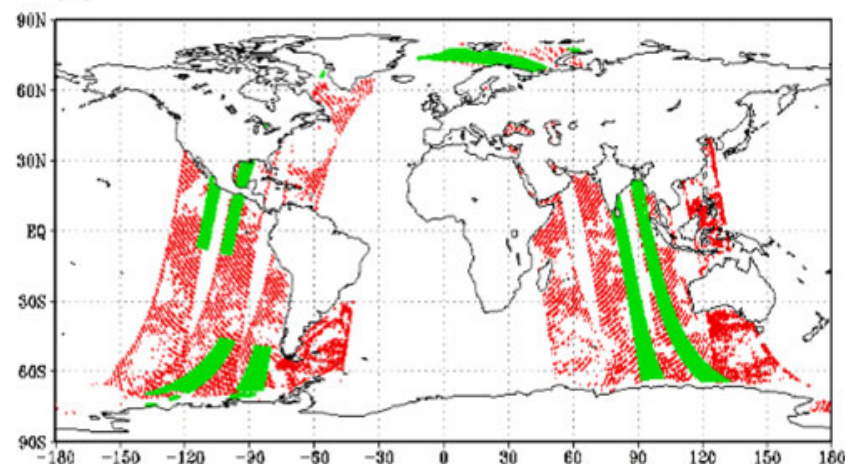

Figure 1. Coverage of OSCAT (red) and ASCAT (green) scatterometer winds available at NCMRWF during different 6 hourly assimilation cycles on a particular day. (a) Centered around 00 UTC (00 \pm 3 UTC), (b) centered around 06 UTC (06 \pm 3 UTC), (c) centered around 12 UTC (12 \pm 3 UTC), and (d) centered around 18 UTC (18 \pm 3 UTC).

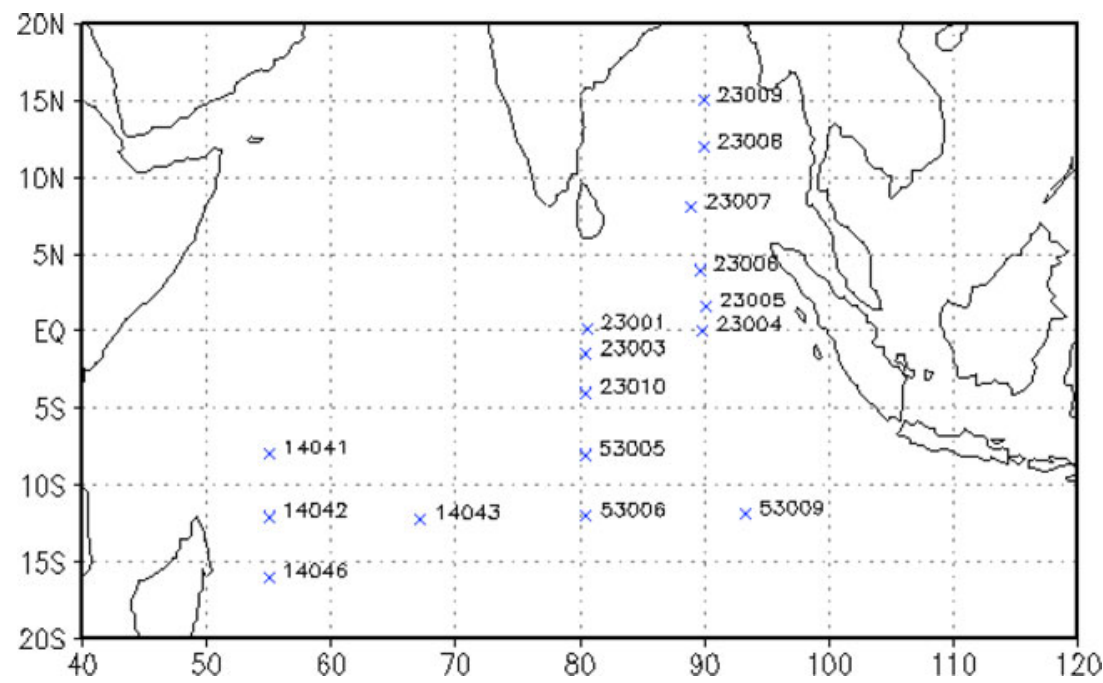

Figure 2. Locations of RAMA buoys with WMO buoy identification number. 
passes of both the satellites over the Indian Ocean is mainly centered on 18 UTC and 06 UTC global model assimilation cycles.

\subsection{RAMA buoy data}

The Tropical Moored Array Programs consist of three different TAO Buoy Arrays. They are TAO/TRITON in the Pacific, Prediction and Research Moored Array (PIRATA) in the Atlantic, and RAMA in the Indian Ocean. Since from implementation, the high quality time series data from these moored arrays improved the understanding and prediction of climate variability and climate change (McPhaden et al. 2009). The measurements on the RAMA surface floats include the meteorological parameters like air temperature, relative humidity, and wind velocity at a height of 3-4 $\mathrm{m}$ above the mean sea level (MSL). Daily averages of all data and several hourly samples per day of most meteorological variables are transmitted to shore in real time via Service Argos. These data placed on the Global Telecommunication System (GTS) for use in operational weather, climate and ocean forecasting (McPhaden et al. 2009). As of now, around 16 moorings are included in the RAMA Buoy Array (http://odis. incois.gov.in/Insitu/Rama_Buoy_Graph.jsp), and figure 2 shows the locations of these buoys with the World Meteorological Organization (WMO) buoy identification number and also described in table 1. NCMRWF is getting the three hourly RAMA buoy data through GTS. NCMRWF archived RAMA buoy data during 2011 is used to compare the scatterometer winds. Figure 3 shows the monthly count

Table 1. WMO buoy identification number and locations of RAMA buoy.

\begin{tabular}{ll}
\hline $\begin{array}{l}\text { WMO buoy } \\
\text { identification number }\end{array}$ & \multicolumn{1}{c}{ Location } \\
\hline 14041 & $7.95^{\circ} \mathrm{S} 55.05^{\circ} \mathrm{E}$ \\
14042 & $12.03^{\circ} \mathrm{S} 54.99^{\circ} \mathrm{E}$ \\
14043 & $12.19^{\circ} \mathrm{S} 67.21^{\circ} \mathrm{E}$ \\
14046 & $16.0^{\circ} \mathrm{S} 55.0^{\circ} \mathrm{E}$ \\
23001 & $0.12^{\circ} \mathrm{N} 80.55^{\circ} \mathrm{E}$ \\
23003 & $1.50^{\circ} \mathrm{S} 80.52^{\circ} \mathrm{E}$ \\
23004 & $0.03^{\circ} \mathrm{N} 89.85^{\circ} \mathrm{E}$ \\
23005 & $1.58^{\circ} \mathrm{N} 90.10^{\circ} \mathrm{E}$ \\
23006 & $3.98^{\circ} \mathrm{N} 89.60^{\circ} \mathrm{E}$ \\
23007 & $8.03^{\circ} \mathrm{N} 88.99^{\circ} \mathrm{E}$ \\
23008 & $11.93^{\circ} \mathrm{N} 89.90^{\circ} \mathrm{E}$ \\
23009 & $14.98^{\circ} \mathrm{N} 89.92^{\circ} \mathrm{E}$ \\
23010 & $3.98^{\circ} \mathrm{S} 80.51^{\circ} \mathrm{E}$ \\
53005 & $8.01^{\circ} \mathrm{S} 80.46^{\circ} \mathrm{E}$ \\
53006 & $12.0^{\circ} \mathrm{S} 80.52^{\circ} \mathrm{E}$ \\
53009 & $11.87^{\circ} \mathrm{S} 93.31^{\circ} \mathrm{E}$ \\
\hline
\end{tabular}

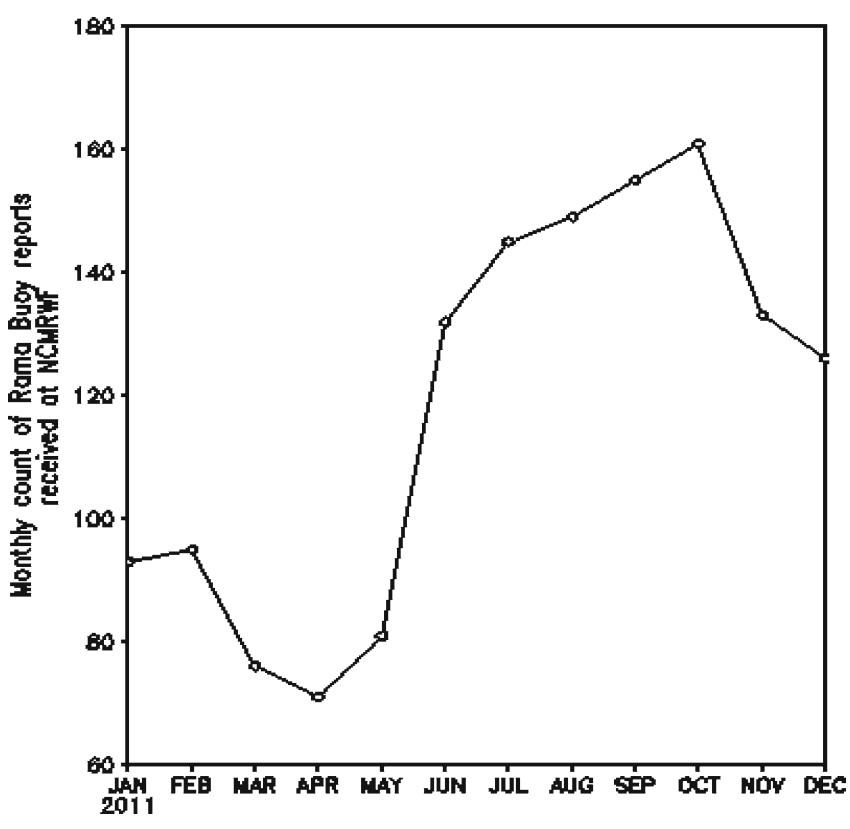

Figure 3. Monthly count of Rama buoy reports (observations) received at NCMRWF in 2011.

of RAMA buoy reports (observations) received at NCMRWF in 2011. It has to be noted from figure 3 that the maximum number of RAMA buoy reports are received during monsoon (checked for other years as well, not shown here). The difference in the monthly count of RAMA buoy reports may be due to vandalism or improper maintenance.

\section{Methodology}

OSCAT data downloaded from NRSC and the RAMA buoy data received at NCMRWF through GTS were used in this study. Apart from the above two datasets, ASCAT winds from NOAA/NESDIS during monsoon 2011 was also used to compare the quality of OSCAT winds in terms of scatterometer winds from other space-borne platforms. Since the scatterometer winds over the ocean surface are provided at $10 \mathrm{~m}$ neutral stability height, the RAMA buoy winds which are reported at $3 \mathrm{~m}$ height is converted to $10 \mathrm{~m}$ to conform to the universally accepted standard level. Even though the RAMA buoys are having temperature and humidity sensors in addition to the wind sensor, most of the time, the humidity information is not available in GTS data. Thus an empirical logarithmic profile method suggested by Peixoto and Oort (1992) is used to convert the $3 \mathrm{~m}$ buoy winds to $10 \mathrm{~m}$ level. If the wind speed at $3 \mathrm{~m}$ and $10 \mathrm{~m}$ are $\mathrm{Ws}(3 \mathrm{~m})$ and $\mathrm{Ws}(10 \mathrm{~m})$ respectively, then

$$
\mathrm{Ws}(10 \mathrm{~m})=\mathrm{Ws}(3 \mathrm{~m}) \frac{\ln \left(Z / Z_{0}\right)}{\ln \left(Z_{\text {ref }} / Z_{0}\right)},
$$


where $Z=10 \mathrm{~m}, Z_{\text {ref }}=3 \mathrm{~m}$ and $Z_{0}=1.52 \times 10^{-4}$. The limitation of this method is that atmospheric stability and the ocean roughness are not taken into account.

The logarithmic profile method and the Liu method (developed at JPL by Liu and Tang (1996), (http://airsea-www.jpl.nasa.gov/publications/ lkb_code.html)) were applied to buoy data in a comparison of SSM/I series of satellite wind and buoy wind by Mears et al. (2001). The Liu method as opposed to the logarithmic profile method, evaluates the atmospheric stability in the computation of wind speed to a standard height. $Z_{0}$ which is the roughness length depends on the roughness of the ocean surface and thus on the wind (stress). Portabella and Stoffelen (2009) reported that $\ln \left(10 / Z_{0}\right)$ values vary between 13 (for low $Z_{0}$ ) and 9 (for high $Z_{0}$ ). From their study, Mears et al. (2001) concluded that using a correction factor, the difference in the results of the logarithmic profile method compared with the Liu approach may be compensated. These investigators also state that the errors induced, excluding atmospheric stability, are small in comparison to other errors, related to the satellite's measurements. To account for the lack of temperature and humidity data, buoy wind has been converted to $10 \mathrm{~m}$ height using the minimal error profile method (Peixoto and Oort 1992). This method requires only the wind speed at the reference height, not the stability parameters (Caballero et al. 2005).

The scatterometer winds were collocated with the buoy winds only if they were spatially within a box of $0.25^{\circ} \times 0.25^{\circ}$ and temporally within 60 minutes. It has also taken into account that each buoy wind was considered only once for collocation within the above spatial and temporal resolution. To ensure that the correct scatterometer wind was selected, the collocated pair was retained only if the difference in the direction between buoy wind and scatterometer wind was less than $60^{\circ}$. Since the mission goal of Oceansat- 2 is to provide wind speed measurements of $4-24 \mathrm{~ms}^{-1}$, the buoy winds whose magnitude below $4 \mathrm{~ms}^{-1}$ were not considered for collocation owing to the difficulty of the scatterometer sensor in measuring directions for low wind speeds. Vogelzang et al. (2011) and Chakraborty et al. (2012) show that the accuracy of buoy winds and scatterometer winds are similar, i.e., the width of their error distribution functions is similar. Throwing the low buoy winds away has the side effect of rejecting negative error realizations more abundantly than positive error realizations for the buoys, but not for the scatterometer, which obviously causes bias. This is, truncation of the buoy error distribution on the negative side, and will increase mean buoy winds relative to the scatterometer winds. In this study, similar threshold has also been applied to the scatterometer winds as well.

Statistical parameters like mean scatterometer wind speed, mean buoy wind speed, speed bias between the scatterometer wind speed and buoy wind speed, root mean square component differences, such as RMSVD for wind speed and root mean square difference (RMSD) for wind direction, and the number of collocated winds were estimated for every month. The statistical parameters are calculated as follows:

$$
\text { Scatterometer wind speed }=\sqrt{S u^{2}+S v^{2}}
$$

$$
\text { Buoy wind speed }=\sqrt{B u^{2}+B v^{2}}
$$

Speed bias $=$ Scatterometer wind speed -

$$
\text { Buoy wind speed }
$$

$$
\begin{gathered}
\text { Vector difference }(\mathrm{VD})=\sqrt{(S u-B u)^{2}+(S v-B v)^{2}} \\
\mathrm{RMSVD}=\sqrt{\frac{\sum V D^{2}}{N}} \\
\mathrm{RMSD}=\sqrt{\frac{(S w d-B w d)^{2}}{N}}
\end{gathered}
$$

where $N$ is the number of collocation (NC) points, $S u$ is the zonal component of scatterometer wind in $\mathrm{ms}^{-1}, S v$ is the meridional component of scatterometer wind in $\mathrm{ms}^{-1}, B u$ is the zonal component of buoy wind in $\mathrm{ms}^{-1}$, and $B v$ is the meridional component of buoy wind in $\mathrm{ms}^{-1}$. Swd and $B w d$ are the scatterometer wind direction and the buoy wind direction, respectively. The error characteristics of the scatterometer winds with respect to the buoy winds along the equator, and over off-equator are also calculated.

Mean monthly vector plots of observed scatterometer winds were generated for monsoon 2011 to see whether the scatterometer winds can capture the low level jet (LLJ), and cross equatorial flow, the lower atmospheric circulations associated with monsoon. Mean vector plots of scatterometer winds are generated by binning the scatterometer winds into $5^{\circ} \times 5^{\circ}$ boxes. Density plots of wind speed, and wind direction were generated for the collocated scatterometer winds and RAMA buoy winds 
(a)

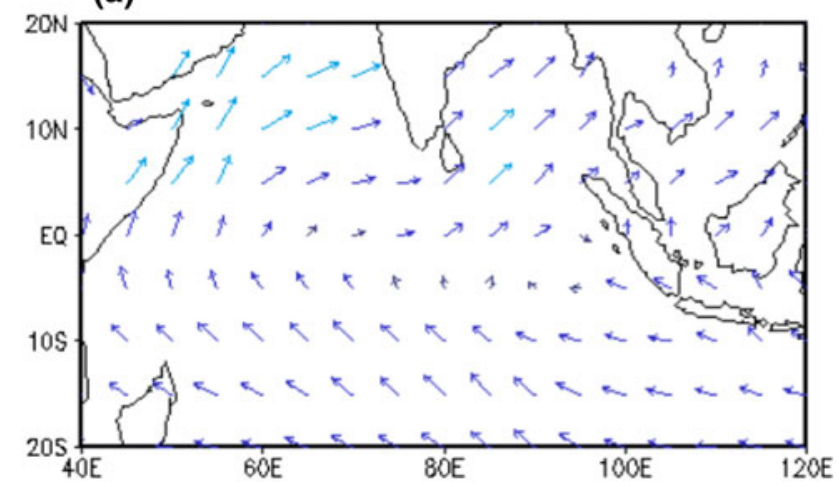

(c)

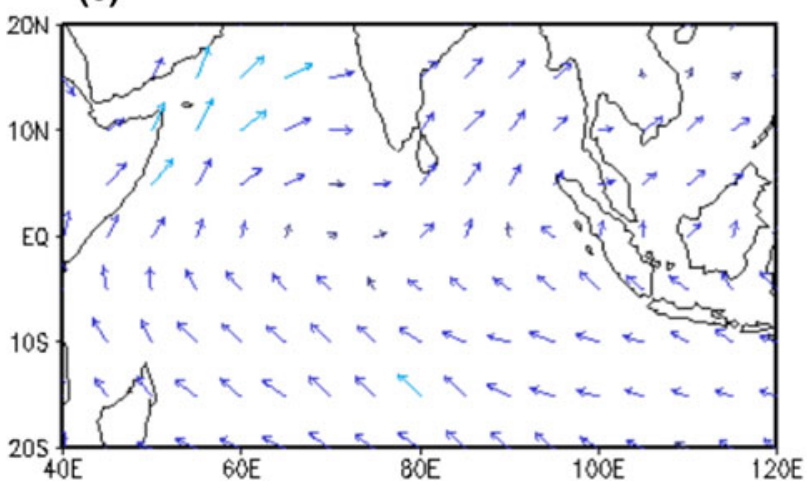

(b)

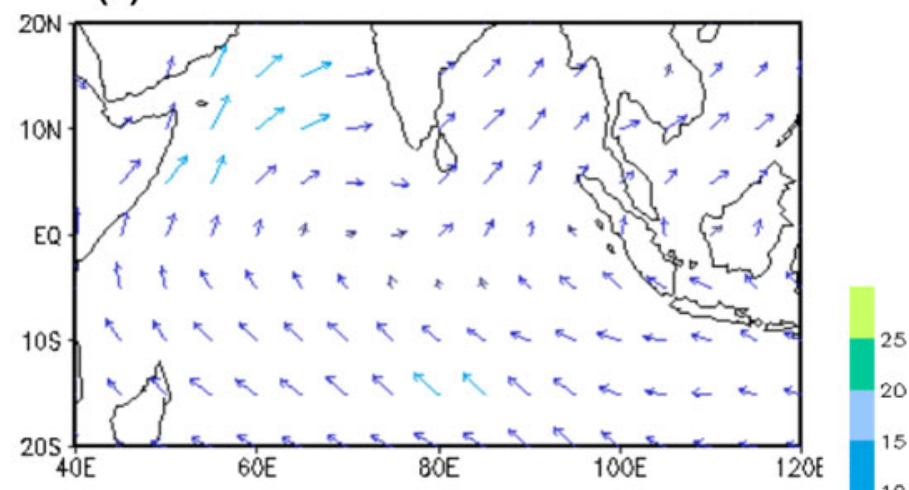

(d)

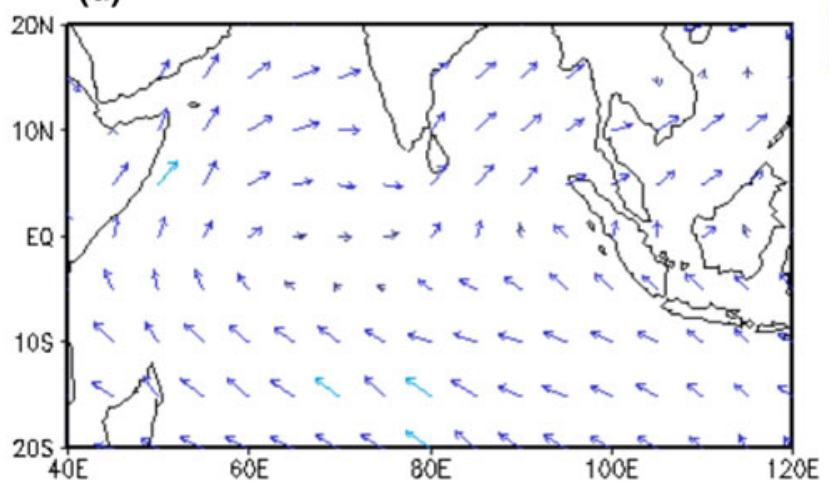

Figure 4. Mean monthly vector plot of OSCAT winds during monsoon 2011. (a) June, (b) July, (c) August and (d) September 2011.

(a)

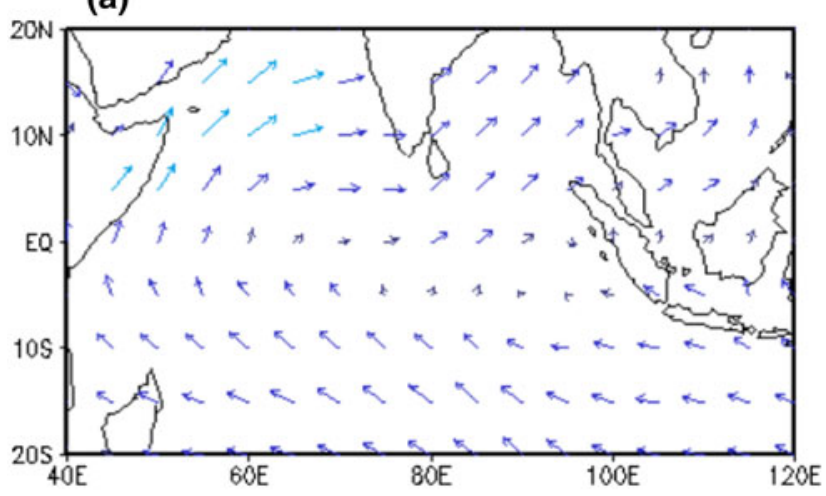

(c)

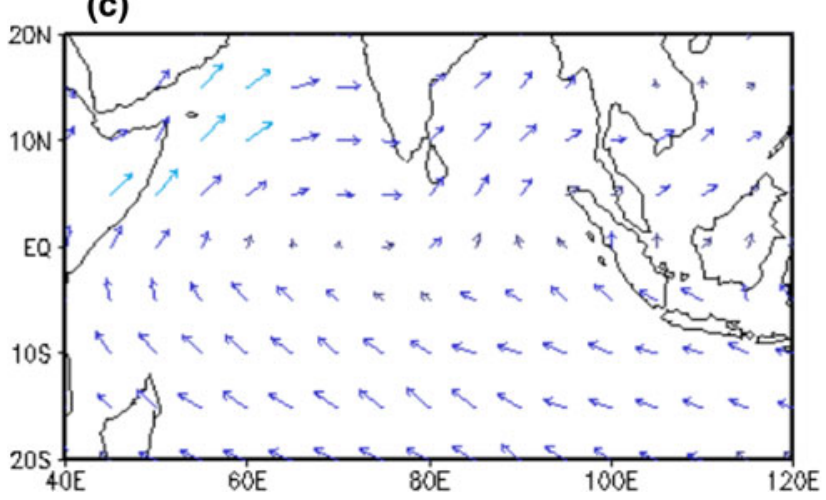

(b)

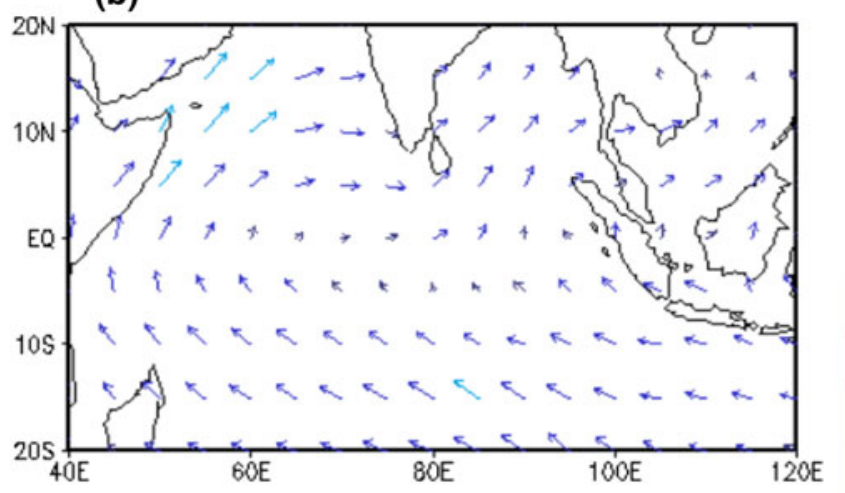

(d)

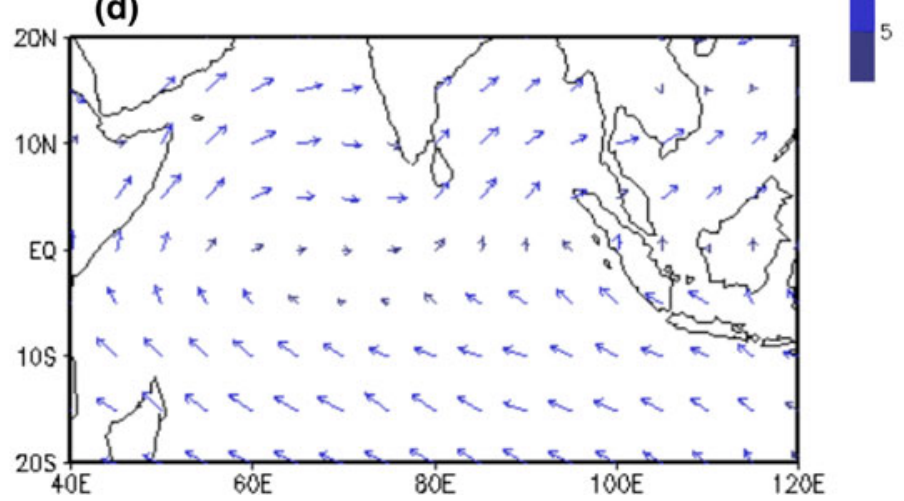

Figure 5. Similar to figure 3, but for ASCAT winds. 
Table 2. Statistical parameters of OSCAT and RAMA buoy wind speed for 2011.

\begin{tabular}{lccccc}
\hline Month & $\begin{array}{c}\text { Mean OSCAT } \\
\text { WS }\left(\mathrm{ms}^{-1}\right)\end{array}$ & $\begin{array}{c}\text { Mean buoy } \\
\text { WS }\left(\mathrm{ms}^{-1}\right)\end{array}$ & $\begin{array}{c}\text { Speed bias } \\
\left(\mathrm{ms}^{-1}\right)\end{array}$ & $\begin{array}{c}\text { RMSVD } \\
\left(\mathrm{ms}^{-1}\right)\end{array}$ & $\begin{array}{r}\text { Number of } \\
\text { collocations }\end{array}$ \\
\hline January & 7.52 & 7.84 & -0.32 & 1.75 & 32 \\
February & 6.56 & 7.26 & -0.69 & 1.80 & 19 \\
March & 6.13 & 7.29 & -1.16 & 2.46 & 15 \\
April & 6.90 & 6.73 & 0.16 & 2.67 & 12 \\
May & 6.74 & 7.37 & -0.62 & 1.72 & 23 \\
June & 8.58 & 9.23 & -0.64 & 1.75 & 27 \\
July & 8.96 & 9.12 & -0.16 & 1.86 & 30 \\
August & 7.42 & 7.74 & -0.32 & 1.55 & 45 \\
September & 6.54 & 7.01 & -0.46 & 1.81 & 32 \\
October & 6.17 & 6.16 & 0.14 & 2.31 & 13 \\
November & 5.42 & 5.29 & 0.12 & 2.10 & 8 \\
December & 7.31 & 7.44 & -0.12 & 2.45 & 10 \\
\hline
\end{tabular}

Table 3. Statistical parameters of OSCAT and RAMA buoy wind direction for 2011.

\begin{tabular}{lccccc}
\hline Month & $\begin{array}{c}\text { Mean OSCAT wind } \\
\text { direction (degrees) }\end{array}$ & $\begin{array}{c}\text { Mean buoy wind } \\
\text { direction (degrees) }\end{array}$ & $\begin{array}{c}\text { Speed bias } \\
\text { (degrees) }\end{array}$ & $\begin{array}{c}\text { RMS (V)D } \\
\text { (degrees) }\end{array}$ & $\begin{array}{c}\text { Number of } \\
\text { collocations }\end{array}$ \\
\hline January & 103.68 & 104.19 & -0.54 & 10.53 & 32 \\
February & 60.27 & 51.38 & 9.41 & 11.85 & 19 \\
March & 63.0 & 67.33 & -4.33 & 15.80 & 15 \\
April & 168.44 & 174.50 & -6.05 & 14.47 & 12 \\
May & 226.91 & 220.00 & 6.91 & 11.17 & 23 \\
June & 223.80 & 220.00 & 3.80 & 10.67 & 27 \\
July & 212.35 & 210.92 & 1.48 & 8.84 & 30 \\
August & 194.43 & 196.41 & -2.13 & 10.11 & 45 \\
September & 172.18 & 171.13 & 1.09 & 10.21 & 32 \\
October & 158.16 & 154.58 & 3.28 & 18.86 & 13 \\
November & 132.21 & 133.57 & -1.35 & 18.01 & 8 \\
December & 120.50 & 125.50 & -5.00 & 15.92 & 10 \\
\hline
\end{tabular}

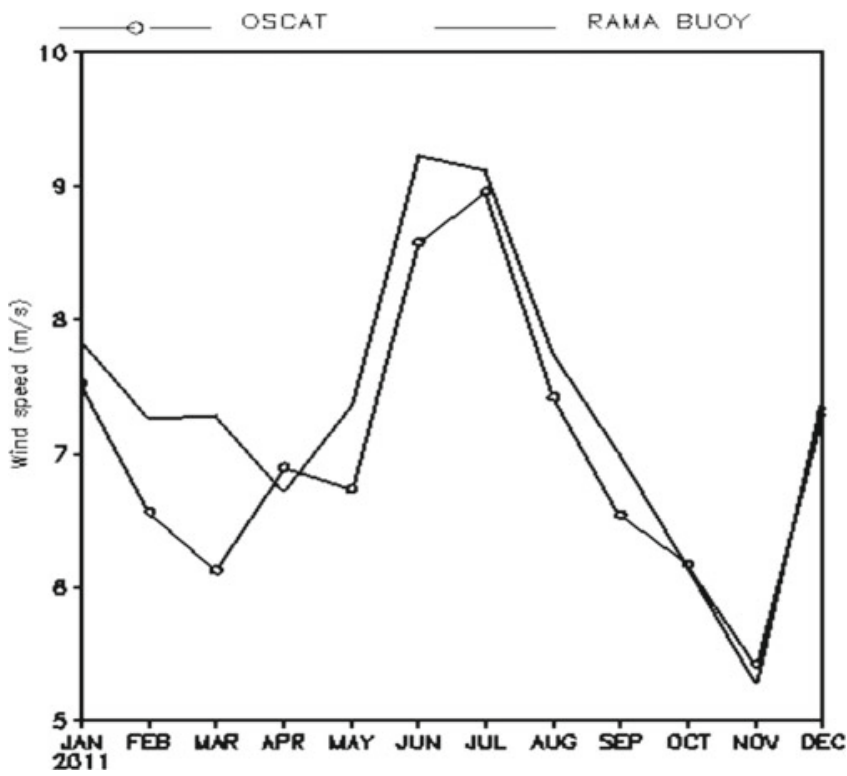

Figure 6. Monthly mean OSCAT (bubbled) and RAMA buoy (continuous) wind speed $\left(\mathrm{ms}^{-1}\right)$ for 2011.

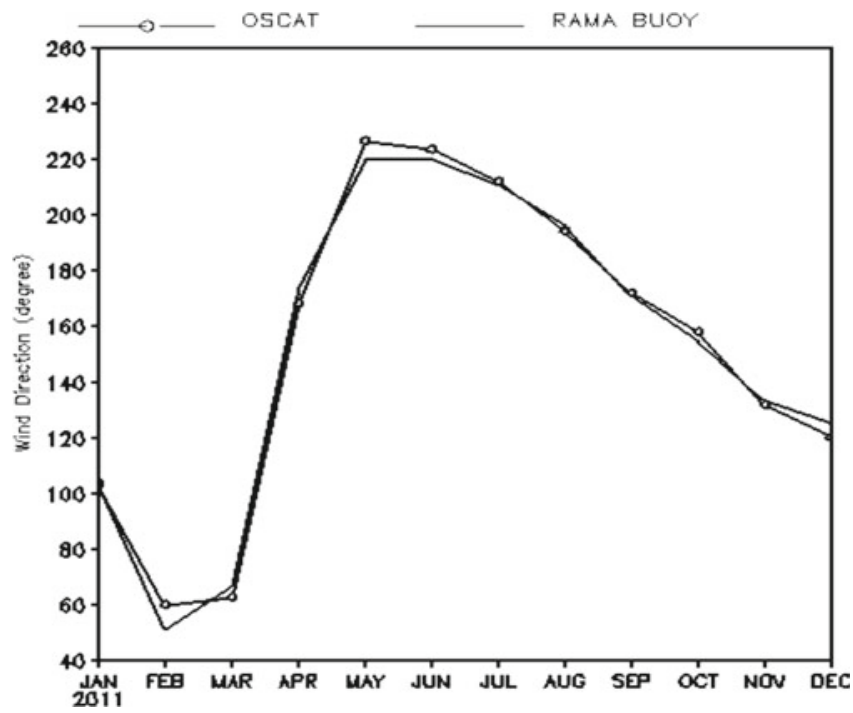

Figure 7. Similar to figure 5, but for wind direction (degrees). 
for monsoon 2011. Density plots are generated by plotting the number of scatterometer winds corresponding to different RAMA buoy winds. These types of plots generally used to identify the errors associated with different wind speed range.

Validation of scatterometer surface winds (both OSCAT and ASCAT) were limited to one year, because the validation results are encouraging and the errors in wind speed and wind direction are observed to be within the mission goal, and the assimilation of these scatterometer winds showed positive impact in global NWP models (Prasad et al. 2013). OSCAT and ASCAT have complementing orbital passes, and the ascending and descending orbital data of both the satellites over the Indian Ocean is segregated everyday during the study period. It is noted that the ascending and descending passes of both the satellites over the Indian Ocean is centred on 18 UTC and 6 UTC assimilation cycles of global models. It was noted that the maximum OSCAT surface winds were available around 06 UTC and in this study the descending orbital pass data was used for collocation for both the scatterometers, however in the scatter plots both descending and ascending orbital passes data during monsoon 2011 were shown.

\section{Results and discussion}

Before comparing the scatterometer winds with RAMA buoy winds, the scatterometer observations were analysed to ensure that these observations could capture the atmospheric circulations on an average scale. Mean monthly vector plots of scatterometer winds were generated during monsoon 2011. One of the salient features of the monsoon circulation is LLJ. LLJ has its origin in

Table 4. Statistical parameters of OSCAT and equatorial RAMA buoy wind speed/direction for 2011.

\begin{tabular}{lcccr}
\hline Month & $\begin{array}{c}\text { Mean OSCAT } \\
\text { ws/wd }\left(\mathrm{ms}^{-1} / \text { degree }\right)\end{array}$ & $\begin{array}{c}\text { Mean buoy } \\
\text { ws/wd }\left(\mathrm{ms}^{-1} / \text { degree }\right)\end{array}$ & $\begin{array}{c}\text { RMSVD/RMSD } \\
\left(\mathrm{ms}^{-1 / \text { degree })}\right.\end{array}$ & $\begin{array}{r}\text { Number of } \\
\text { collocations }\end{array}$ \\
\hline January & $6.40 / 283.0$ & $7.14 / 276.66$ & $1.08 / 6.33$ & 3 \\
February & $4.90 / 209.0$ & $4.59 / 220.0$ & $0.95 / 11.0$ & 1 \\
March & Nil & Nil & Nil & Nil \\
April & $7.30 / 273.6$ & $6.16 / 286.6$ & $3.99 / 23.0$ & 3 \\
May & $8.69 / 271.0$ & $8.63 / 250.0$ & $3.16 / 21.0$ & 1 \\
June & $6.50 / 242.5$ & $7.32 / 231.6$ & $1.70 / 10.83$ & 6 \\
July & $6.09 / 215.3$ & $7.92 / 206.6$ & $2.15 / 8.66$ & 3 \\
August & $5.06 / 161.3$ & $5.80 / 166.8$ & $1.44 / 10.75$ & 16 \\
September & $5.83 / 158.3$ & $6.34 / 155.0$ & $1.91 / 10.78$ & 6 \\
October & $5.78 / 168.0$ & $6.05 / 166.6$ & $1.44 / 11.6$ & 3 \\
November & $5.03 / 197.6$ & $5.60 / 183.3$ & $2.24 / 21.0$ & 2 \\
December & $7.25 / 308.0$ & $5.44 / 300.0$ & $3.60 / 8.00$ & 3 \\
\hline
\end{tabular}

Table 5. Statistical parameters of OSCAT and north equatorial RAMA buoy wind speed/direction for 2011.

\begin{tabular}{|c|c|c|c|c|}
\hline Month & $\begin{array}{c}\text { Mean OSCAT } \\
\text { ws/wd }\left(\mathrm{ms}^{-1} / \text { degree }\right)\end{array}$ & $\begin{array}{c}\text { Mean buoy } \\
\text { ws/wd }\left(\mathrm{ms}^{-1} / \text { degree }\right)\end{array}$ & $\begin{array}{l}\text { RMSVD/RMSD } \\
\left(\mathrm{ms}^{-1} / \text { degree }\right)\end{array}$ & $\begin{array}{l}\text { Number of } \\
\text { collocations }\end{array}$ \\
\hline January & $7.57 / 71.56$ & $8.02 / 74.37$ & $1.71 / 10.15$ & 25 \\
\hline February & $6.61 / 56.00$ & $7.34 / 46.66$ & $1.81 / 11.64$ & 18 \\
\hline March & $6.13 / 63.00$ & $7.29 / 67.33$ & $2.46 / 15.80$ & 15 \\
\hline April & $5.92 / 170.00$ & $5.15 / 172.50$ & $3.11 / 20.00$ & 4 \\
\hline May & $6.71 / 229.90$ & $7.44 / 223.80$ & $1.68 / 10.76$ & 21 \\
\hline June & $9.11 / 235.26$ & $9.93 / 233.66$ & $1.60 / 9.38$ & 16 \\
\hline July & $9.26 / 213.67$ & $9.30 / 212.80$ & $1.78 / 8.56$ & 25 \\
\hline August & $8.77 / 218.52$ & $9.07 / 219.56$ & $1.44 / 8.27$ & 23 \\
\hline September & $6.93 / 225.81$ & $7.72 / 230.62$ & $1.26 / 8.07$ & 9 \\
\hline October & $5.90 / 140.00$ & $5.15 / 165.00$ & $3.23 / 33.00$ & 2 \\
\hline November & $4.83 / 60.33$ & $4.41 / 76.66$ & $1.51 / 16.33$ & 3 \\
\hline December & $7.22 / 57.37$ & $7.79 / 67.50$ & $2.27 / 19.12$ & 8 \\
\hline
\end{tabular}


the south Indian Ocean north of the Masacarence High as an easterly current. It crosses the equator in a narrow longitudinal belt close to the east African coast as southerly current and then turns into Arabian Sea as a westerly current. LLJ transports the moisture from the Indian Ocean to the Indian landmass. Joseph and Raman (1966) and Findlater (1966) first pointed out the existence of Monsoon Low Level Jet (MLLJ) over peninsular India. Figures 4 and 5 show the vector plots of OSCAT and ASCAT winds during monsoon 2011 over the oceanic region surrounding India and the neighbouring landmass. Both OSCAT and ASCAT winds clearly depict the important features of the Indian summer monsoon circulation, such as the cross-equatorial flow along the East African coast, the LLJ and associated peak winds over the Arabian Sea, relatively calm winds a few degrees of latitudes on either side of the equator and easterly trade winds of southern hemisphere. Sathiyamoorthy et al. (2012) also reported these kinds of monsoonal features in OSCAT surface winds.

Tables 2 and 3 show the monthly mean wind speed and wind direction statistics of OSCAT winds with respect to the RAMA buoy winds for different months in 2011. These tables describe the mean OSCAT wind speed/direction, mean buoy wind speed/direction, the bias, the RMSVD/RMSD and the number of collocated winds. It was noted that the buoy measured mean speed was always higher than that of OSCAT. It suggests that the OSCAT winds have a slow (negative) bias with respect to buoy winds over the Indian Ocean. Figure 6 shows the monthly mean wind speed from the OSCAT and RAMA buoy for 2011. It is obvious from figure 6 that the buoy wind speed is always higher than that of OSCAT wind speed. The monthly mean RMSVD in wind speed was observed to be below $2.5 \mathrm{~ms}^{-1}$. It was also noted that during Indian summer monsoon period, the RMSVD $\left(1.9 \mathrm{~ms}^{-1}\right)$ reduced significantly. The

Table 6. Statistical parameters of OSCAT and south equatorial RAMA buoy wind speed/direction for 2011.

\begin{tabular}{llccc}
\hline Month & $\begin{array}{c}\text { Mean OSCAT } \\
\left.\text { ws } / \mathrm{wd}^{-1} / \text { degree }\right)\end{array}$ & $\begin{array}{c}\text { Mean buoy } \\
\text { ws/wd }\left(\mathrm{ms}^{-1} / \text { degree }\right)\end{array}$ & $\begin{array}{c}\text { RMSVD/RMSD } \\
\left(\mathrm{ms}^{-1} / \text { degree }\right)\end{array}$ & $\begin{array}{c}\text { Number of } \\
\text { collocations }\end{array}$ \\
\hline January & $8.25 / 273.50$ & $8.21 / 260.00$ & $2.76 / 13.50$ & 4 \\
February & $\mathrm{Nil}$ & $\mathrm{Nil}$ & $\mathrm{Nil}$ & $\mathrm{Nil}$ \\
March & $\mathrm{Nil}$ & $\mathrm{Nil}$ & $\mathrm{Nil}$ & $\mathrm{Nil}$ \\
April & $7.50 / 115.80$ & $8.05 / 128.00$ & $2.01 / 12.19$ & 5 \\
May & $5.40 / 120.00$ & $4.59 / 110.00$ & $1.18 / 10.00$ & 1 \\
June & $9.85 / 126.40$ & $9.71 / 134.00$ & $2.16 / 13.00$ & 5 \\
July & $8.35 / 160.50$ & $6.61 / 165.00$ & $2.10 / 9.50$ & 2 \\
August & $7.38 / 143.33$ & $6.82 / 133.33$ & $2.23 / 15.00$ & 6 \\
September & $7.14 / 135.88$ & $7.50 / 137.77$ & $1.81 / 8.37$ & 9 \\
October & $6.61 / 138.80$ & $6.37 / 130.00$ & $3.19 / 25.60$ & 5 \\
November & $6.80 / 126.00$ & $6.39 / 135.00$ & $2.98 / 15.00$ & 2 \\
December & Nil & Nil & Nil & Nil \\
\hline
\end{tabular}

Table 7. Statistical parameters of OSCAT and ASCAT with respect to RAMA buoy winds during monsoon 2011.

\begin{tabular}{|c|c|c|c|c|c|c|c|c|}
\hline \multirow[b]{2}{*}{ Parameter } & \multicolumn{2}{|c|}{ June 2011} & \multicolumn{2}{|c|}{ July 2011} & \multicolumn{2}{|c|}{ August 2011} & \multicolumn{2}{|c|}{ September 2011} \\
\hline & OSCAT & ASCAT & OSCAT & $\overline{\mathrm{ASCAT}}$ & OSCAT & $\overline{\mathrm{ASCAT}}$ & OSCAT & ASCAT \\
\hline Mean scat ws & 8.58 & 8.49 & 8.96 & 8.51 & 7.42 & 8.14 & 6.54 & 8.75 \\
\hline Mean buoy ws & 9.23 & 8.67 & 9.12 & 8.87 & 7.74 & 8.31 & 7.01 & 8.79 \\
\hline Speed bias & -0.64 & -0.22 & -0.16 & -0.36 & -0.32 & -0.17 & -0.46 & -0.36 \\
\hline RMSVD & 1.75 & 1.90 & 1.86 & 1.93 & 1.55 & 1.62 & 1.81 & 1.82 \\
\hline No. of collocations & 27 & 18 & 30 & 32 & 45 & 38 & 32 & 36 \\
\hline Mean scat wd & 223.80 & 185.04 & 212.35 & 159.21 & 194.43 & 155.75 & 172.18 & 153.90 \\
\hline Mean buoy wd & 220.00 & 187.08 & 210.92 & 161.35 & 196.41 & 155.04 & 171.13 & 158.54 \\
\hline Wd bias & 3.80 & -2.04 & 1.48 & -2.13 & -2.13 & 0.80 & 1.09 & -4.64 \\
\hline RMSD & 10.67 & 12.14 & 8.84 & 11.62 & 10.11 & 10.78 & 10.21 & 10.80 \\
\hline No. of collocations & 27 & 18 & 30 & 32 & 45 & 38 & 32 & 36 \\
\hline
\end{tabular}


number of collocations also increased during monsoon period. NCMRWF archived RAMA buoy data also showed maximum RAMA buoy reports during monsoon period (figure 3 ).

From table 3, it is clear that the monthly mean wind direction from OSCAT and buoy were comparable. Figure 7 is similar to figure 6 , but for wind direction. The bias and RMSD in wind direction of OSCAT with respect to the buoy winds also showed less value during monsoon, as seen in the wind speed. Tables $4-6$ show the monthly mean wind parameters (wind speed and direction) statistics of OSCAT winds against the buoy winds over the equator, north of equator and south of equator respectively for 2011. Over these three regions, the monthly RMSVD/RMSD in the wind speed/direction was within the mission goal especially during monsoon. Monsoon circulation features like relatively calm winds a few degrees of latitudes on either side of the equator (table 4), strong westerly over the north of equator (table 5) and easterly trade winds of the southern hemisphere (table 6) are noticed both in the scatterometer and buoy winds.

The ASCAT winds were also compared against RAMA buoy winds in addition to the OSCAT winds, during monsoon 2011 in order to assess the performance of OSCAT winds in terms of other scatterometer wind products. The statistics of OSCAT and ASCAT winds with respect to
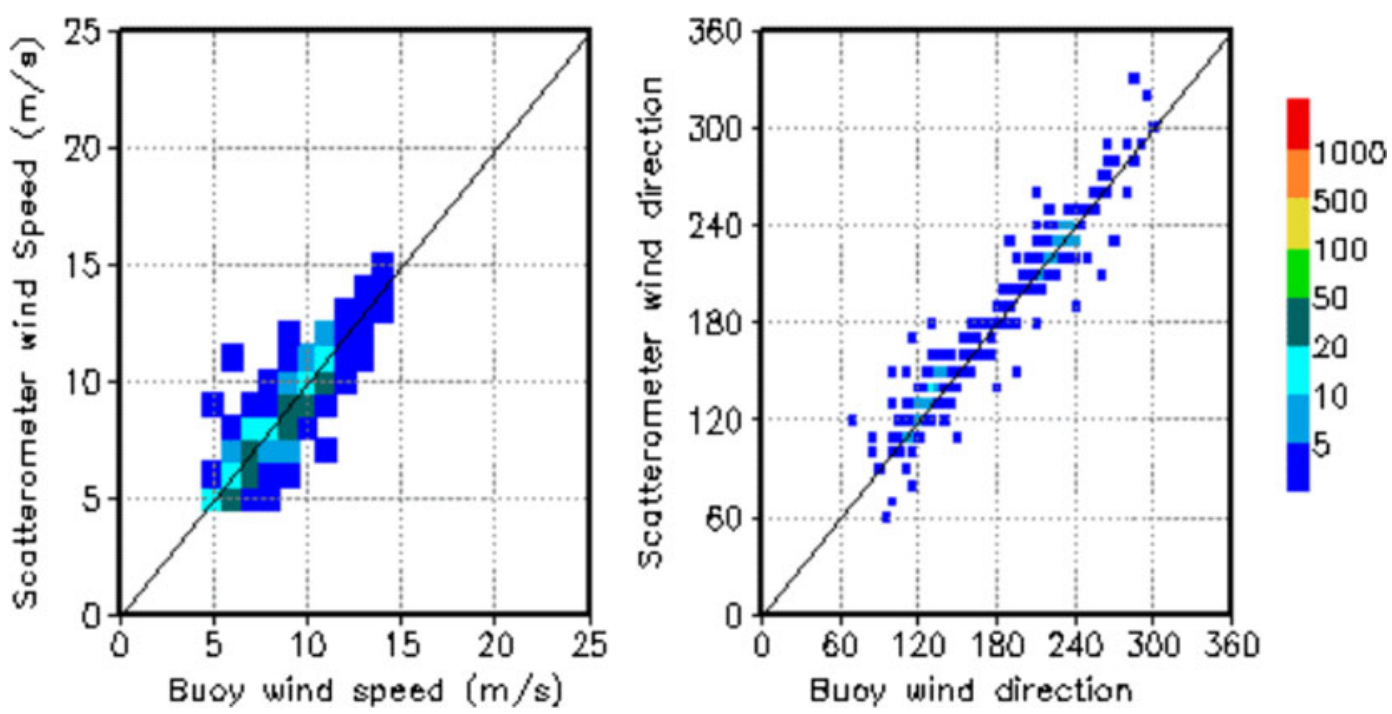

Figure 8. Density plots of OSCAT wind parameters (wind speed and wind direction) against the corresponding RAMA buoy parameters for monsoon 2011.
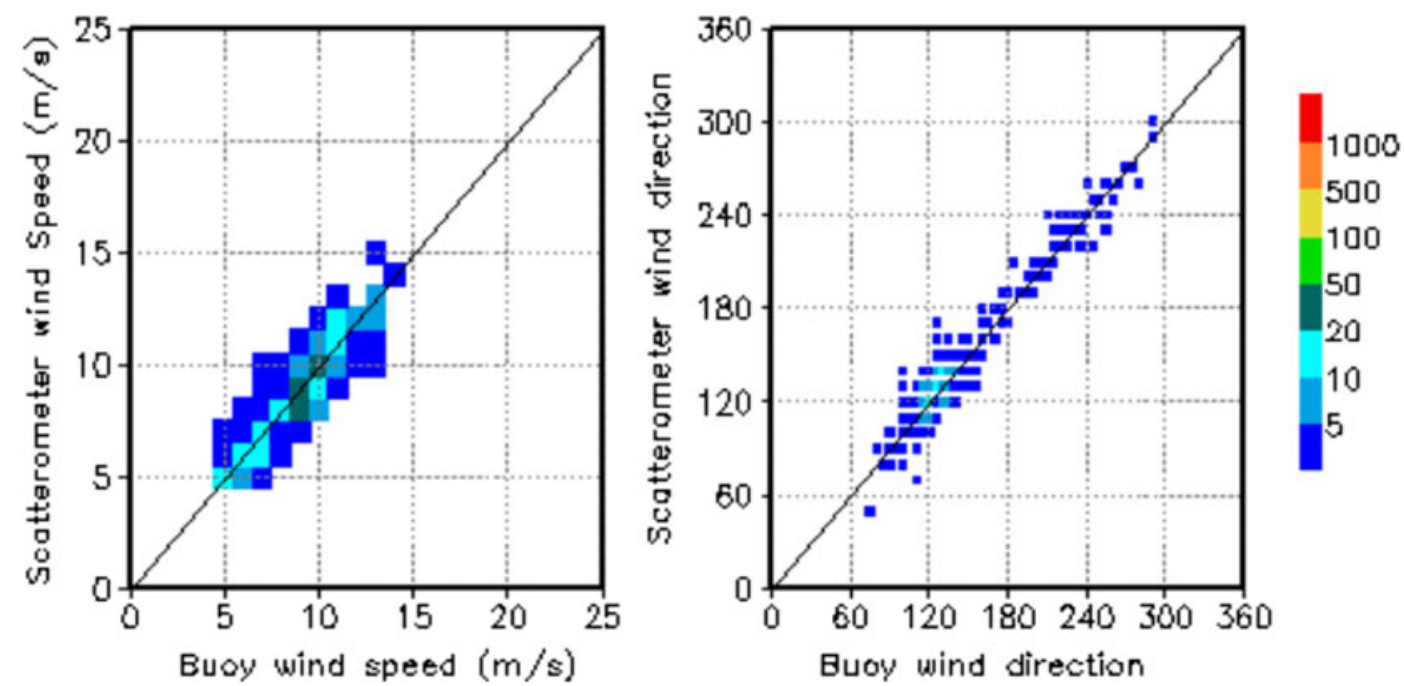

Figure 9. Similar to figure 7, but for ASCAT. 
RAMA buoy winds during monsoon 2011 were tabulated in table 7 . Both the scatterometer winds showed slow (negative) bias with respect to the buoy winds. The root mean squared differences in wind speed and wind direction of both the scatterometer winds with respect to the RAMA buoy winds were within the mission requirement. The numbers of collocated winds from both the scatterometers were also comparable.

Figures 8 and 9 are the density plots of wind speed, and wind direction from OSCAT and ASCAT against RAMA buoy winds for monsoon 2011. In these figures, (a) and (b) represent the wind speed, and wind direction respectively. Wind speeds were segregated into $1 \mathrm{~ms}^{-1}$ bins and wind direction to $5^{\circ}$ bins. Standard deviation of OSCAT and ASCAT scatterometer wind speed (wind direction) with respect to RAMA buoy winds during monsoon 2011 were $1.03 \mathrm{~ms}^{-1}\left(21.47^{\circ}\right)$ and $0.91 \mathrm{~ms}^{-1}\left(21.06^{\circ}\right)$, respectively.

\section{Conclusions}

Sea surface winds from OSCAT over the Indian Ocean are evaluated against the RAMA buoy winds during 2011. Validation of OSCAT winds against RAMA buoy winds during 2011 showed maximum collocations in the Indian summer monsoon season. In general OSCAT winds showed slow (negative) bias with respect to the RAMA buoy winds. The comparisons of scatterometer and buoy winds which are temporally and spatially separated within 60 minutes and $0.25^{\circ}$ showed that the wind speeds and directions observed by OSCAT agree with RAMA buoy winds. The monthly root mean square difference in the wind speed and wind direction are approximately in the range of $1.5-2.5 \mathrm{~ms}^{-1}$ and $15^{\circ}-8^{\circ}$, respectively. Better agreement between the OSCAT and RAMA buoy winds were observed during Indian summer monsoon season with root mean square differences in wind speed and wind direction $\sim 1.5-1.8 \mathrm{~ms}^{-1}$ and $\sim 11^{\circ}-8^{\circ}$, respectively. Collocation of scatterometer winds against equatorial and off-equatorial buoys clearly brought out the monsoon circulation features. Collocation exercise of ASCAT winds with respect to RAMA buoy winds during monsoon period also showed that the OSCAT wind statistics are comparable with that of ASCAT over the Indian Ocean.

\section{Acknowledgement}

Authors are grateful to the Director, NCMRWF for the encouragement.

\section{References}

Caballero A, Sagarminaga Y and Espino M 2005 The relationship between satellite and meteorological modelderived winds with those from ocean buoys within the Bay of Biscay; J. Atmos. Ocean Sci. 10(4) 463-479.

Chakraborty A, Kumar R and Stoffelen A 2012 Validation of ocean surface winds from the OCEANSAT-2 scatterometer using triple collocation; Rem. Sens. Lett. 4 85-91, doi: 10.1080/2150704x.2012.693967.

de Ruijter W P M, Biastoch A, Drijfhout S S, Lutjeharms J R E, Matano R P, Pichevin T, van Leeuwen P J and Weijer W 1999 Indian-Atlantic inter-ocean excange: Dynamics, estimation and impact; J. Geophys. Res. 104(C9) 20,885-20,910.

Findlater J 1966 Cross-equatorial jet streams at low level over Kenya; Meteor. Mag. 95 353-364.

Gohil B S, Sarkar A and Agarwal V K 2008 A new algorithm for wind vector retrieval from scatterometer; IEEE Trans. Geosci. Rem. Sens. Lett. 5 387-391.

Gohil B S, Sharma P, Sikhakoli R and Sarkar A 2010 Directional stability and conservation of scattering (DiSCS) based directional-ambiguity removal algorithm for improving wind-fields from scatterometer: A QuickSCAT example; IEEE Trans. Geosci. Rem. Sens. Lett. 7 592-595.

Gordon A L 2001 Interocean exchange; In: Ocean Circulation and Climate (eds) Siedler G, Church J and Gould J, Academic Press, pp. 303-314.

Goswami B N and Rajagopal E N 2003 Indian Ocean surface winds from NCMRWF analysis as compared to QuikSCAT and moored buoy winds; Proc. Indian Acad. Sci (Earth Planet. Sci.) 112 61-77.

Goswami B N and Sengupta D 2003 A note on the deficiency of NCEP/NCAR reanalysis surface winds over the equatorial Indian Ocean; J. Geophys. Res. 108(C4) 3124, doi: 10.1029/2002JC001497.

Joseph P V and Raman P L 1966 Existence of low-level westerly jet stream over peninsular India during July; Ind. J. Meteorol. Geophys. 17 407-410.

Liu W T and Tang W 1996 Equivalent Neutral Wind; JPL Publ. 96-17, Jet Propulsion Laboratory, Pasadena, US, $16 \mathrm{p}$.

McPhaden M J, Meyers G, Ando K, Masumoto Y, Murty V S N, Ravichandran M, Syamsudin F, Vialard J, Yu L and Yu W 2009 RAMA The Research Moored Array for African-Asian-Australian monsoon analysis and prediction; Bull. Am. Meteor. Soc. 90 459-480.

Mears C, Smith D and Wentz F J 2001 Comparison of SSM/I and buoy-measured wind speeds from 1987 to 1997 ; J. Geophys. Res. 106 11,719-11,729.

Peixoto J P and Oort A H 1992 Physics of Climate (Woodbury, NY: American Institute of Physics).

Portabella M and Stoffelen A 2009 On scatterometer ocean stress; J. Atmos. Ocean. Technol. 26(2) 368-382, doi: 10.1175/2008JTECHO578.1.

Prasad V S, Gupta A, Rajagopal E N and Basu S 2013 Impact of Oscat surface wind data on T574L64 assimilation and forecasting system - a study involving tropical cyclone Thane; Curr. Sci. 104(5) 627-631.

Satheesan K, Sarkar A, Parekh A, Rameshkumar and Kuroda Y 2007 Comparison of wind data from QuikSCAT and buoys in the Indian Ocean; Int. J. Remote Sens. 28 $2375-2382$.

Sathiyamoorthy V, Sikhakolli R, Gohil B S and Pal P K 2012 Intra-seasonal variability in Oceansat-2 scatterometer sea-surface winds over the Indian summer monsoon region; Meteorol. Atmos. Phys., doi: 10.1007/s00703-0120189-5. 
Singh R, Kumar P and Pal P K 2011 Assimilation of Oceansat-2-scatterometer-derived surface winds in the weather research and forecasting model; IEEE Trans. Geosci. Remote Sens., doi: 10.1109/TGRS.2011.2164410. Stoffelen A, Vogelzang J and Verhoef A 2010 Verification of scatterometer winds; 10th International Winds Workshop, 20/2/2010-26/2/2010, (eds) Forsythe M and Daniels J, Tokyo, Japan, JMA, EUMETSAT, Volledige tekst.
Sudha A K and Prasada Rao C V K 2013 Comparison of Oceansat-2 scatterometer winds with buoy observations over the Indian Ocean and the Pacific Ocean; Rem. Sens. Lett. 4(2) 171-179, doi: 10.1080/2150704X.2012. 713140 .

Vogelzang J, Stoffelen A, Verhoef A and Figa-Saldana J 2011 On the quality of high-resolution scatterometer winds; J. Geophys. Res. 116 C10033, doi: 10.1029/ 2010jC006640.

MS received 6 February 2013; revised 10 May 2013; accepted 26 May 2013 